\title{
Walton Bridge - a new arch bridge over the River Thames, UK
}

1 Chris R. Hendy FREng, MA(Cantab), CEng, FICE, Eur Ing Head of Bridge Design and Technology, Transportation, Atkins, Epsom, UK

2 David A. Smith BEng, CEng, FICE

Structures Practice Director, Transportation, Atkins, Epsom, UK (corresponding author: david.a.smith@atkinsglobal.com)
3 Manuela Chiarello MEng, PhD, CEng, MICE Senior Engineer, Transportation, Atkins, Epsom, UK
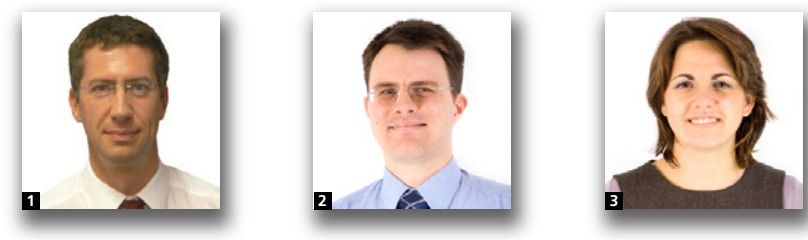

Walton Bridge comprises a steel thrust arch with pad foundations supporting a steel-concrete composite ladder deck. The arch ribs have parabolic profile and varying hexagonal cross-section, tapering from springing points to crown, and span $96.1 \mathrm{~m}$. The total rise of the arch is $14.77 \mathrm{~m}$ with a span to rise ratio of 6.5 . The bridge deck is suspended from the arch by bar-type hangers. Continuous end spans carry the bridge deck between the arch and end abutments, which are full-height reinforced concrete. This paper discusses the method of design employed, including the impact of construction methodology and environmental constraints, together with analysis of aerodynamic effects. It focuses on a number of innovations that were introduced and challenges that were resolved. Two key issues had to be addressed. First, the arch design utilising plastic section properties with reductions to account for the continuously curved steel plating making up the arch ribs. This required local non-linear analysis to demonstrate that the curved arch plating had similar, but slightly reduced, strength and ductility to an equivalent flat plate with the same width and thickness. Hand calculation methods were developed from the results of the analysis. Second, the design and specification of bar-type arch hangers for brittle fracture and fatigue, with insufficient industry guidance on either subject: there is little codified guidance on toughness requirements for bars or on fatigue testing taking angular tolerances at end connections into account, arising both from initial setting-out tolerances and displacements in service from variable actions including temperature effects.

\section{Notation}

$\begin{array}{ll}a & \text { panel length } \\ B & \text { bar diameter } \\ b & \text { panel width } \\ C_{\mathrm{V}} & \text { Charpy value } \\ c & \text { width or depth of a part of a cross-section } \\ d & \text { depth of section } \\ f_{\mathrm{y}} & \text { yield strength } \\ K_{1 \mathrm{c}} & \text { plane strain fracture toughness for linear elastic } \\ & \text { behaviour measured in } \mathrm{N} / \mathrm{mm}^{3 / 2} \\ L & \text { length of cable } \\ M_{y, \mathrm{Ed}} & \text { design bending moment, } y-y \text { axis }\end{array}$

$M_{y, \mathrm{Rd}} \quad$ design values of resistance to bending moments, $y-y$ axis

$M_{z, \text { Ed }} \quad$ design bending moment, $z-z$ axis

$M_{z, \mathrm{Rd}} \quad$ design values of resistance to bending moments, $z-z$ axis

$N_{\text {cr,ip }} \quad$ in-plane buckling load

$N_{\text {cr,op }} \quad$ out-of-plane buckling load

$N_{\text {Ed }}$ design value of axial force

$N_{\text {pl,Rd }}$ design plastic resistance to normal forces of the gross cross-section

$N_{\mathrm{Rk}} \quad$ characteristic resistance to normal force of the critical cross-section 


\begin{tabular}{|c|c|}
\hline$P_{\mathrm{b}}$ & aerodynamic susceptibility parameter \\
\hline$r$ & plate radius \\
\hline$t$ & plate thickness \\
\hline$\alpha_{\mathrm{cr}}$ & $\begin{array}{l}\text { minimum load factor against elastic critical buckling } \\
\text { of the arch }\end{array}$ \\
\hline$\alpha_{\mathrm{cr}, \mathrm{ip}}$ & lowest of the buckling factors for in-plane buckling \\
\hline$\alpha_{\mathrm{cr}, \mathrm{op}}$ & $\begin{array}{l}\text { lowest of the buckling factors for out-of-plane } \\
\text { buckling }\end{array}$ \\
\hline$\alpha_{\mathrm{ult}, \mathrm{k}}$ & $\begin{array}{l}\text { minimum load amplifier of design loads to reach the } \\
\text { characteristic resistance of the most critical } \\
\text { cross-section }\end{array}$ \\
\hline $\bar{\lambda}$ & non-dimensional slenderness \\
\hline$\sigma_{\mathrm{uk}}$ & characteristic value of breaking stress \\
\hline & reduction factor for relevant buckling curve \\
\hline
\end{tabular}

\section{Introduction and project background}

A new bridge over the River Thames was promoted by Surrey County Council (SCC) as a major improvement scheme to replace two existing temporary bridges over the river at Walton-on-Thames.

In 2005, SCC awarded the early contractor involvement contract to Costain, with Atkins as designer. The proposed crossing was to carry the A244 over the river with a single $114 \mathrm{~m}$ span arch. The type of arch and the choice of material were to be developed by the contractor, but the arrangement of two hexagonal-shaped arch ribs inclined by $5^{\circ}$ was fixed as an important aesthetic parameter. The deck was also to be kept as slender as possible, with clean lines on the outer edge.

The solution initially chosen was a steel thrust arch bridge rising from low-height springing points at riverbank level to a crown $23.5 \mathrm{~m}$ above the river, giving a span to rise ratio of $5 \cdot 5$. The bridge had two short back spans to reach abutments set further back from the edge of the river to give an overall length of $125 \mathrm{~m}$. On the Walton side of the river, the existing sub-standard T-junction was to be replaced with a twin-arm junction with a loop road under the new bridge. This was intended to ease entry into the side road.

In 2006, a public inquiry concluded that the twin-arm junction was not in keeping with the existing recreational use of the riverside, known locally as Cowey Sale. The scheme was thus not confirmed and SCC was asked to reconsider the proposals for the twin-arm junction. A revised scheme was granted planning approval in 2008. The Secretary of State gave consent to the Bridge Order and compulsory land purchase in 2009, with full approval given in December 2010 following a governmental comprehensive spending review.

The rejection of the junction arrangement in 2006 gave the project team the opportunity to revisit the bridge design and some constraints were revised in order to improve the bridge and address some of the comments raised during the public inquiry. The twin-arm junction between the A244 and the side road (Walton Lane) was changed to a ghost island arrangement further away from the bridge. Instead of a loop road, an access track was provided for access to a local marina. With the deck level set by the navigation headroom requirement of $6.0 \mathrm{~m}$, the access track was permitted to have a reduction in standard headroom of $5.3 \mathrm{~m}$ down to $4.5 \mathrm{~m}$, thereby keeping the new A244 at a similar level to the existing bridges.

The requirement to span the River Thames without piers in the channel remained, but the span could be reduced by not having to cross the loop road. At a span of $96.1 \mathrm{~m}$ between springing there was still sufficient space to accommodate the $11 \mathrm{~m}$ wide strip of open land required for the long-distance Thames Path. The arch crown was lowered by $5.8 \mathrm{~m}$ so that it was less dominant over the nearby flats. This increased the span to depth ratio to $6 \cdot 5$. Instead of the single back span, two back spans were provided on each side, increasing the overall length to $148 \mathrm{~m}$ and creating a more open aspect for visitors on the river and those on foot. A general arrangement of the final design is shown in Figure 1(a), a photomontage in Figure 1(b) and a cross-section in Figure 1(c).

\section{Walton Bridge overview}

With the key form of the bridge agreed, the remaining aspects of the design were developed with strong emphasis on aesthetics. The hexagonal parabolic arch was tapered from a depth of $2.5 \mathrm{~m}$ (between vertices) at the springing points to $1.5 \mathrm{~m}$ at the crown. The minimum cross-section was dictated by internal access requirements. Generally, the arch internal access openings were $900 \mathrm{~mm}$ high but this was reduced at the crown diaphragm to $600 \mathrm{~mm} \times 600 \mathrm{~mm}$ for structural reasons; this was considered the minimum negotiable while wearing breathing apparatus. Grab handles and steps were included to help with internal inspection access.

The arch springing points were reinforced concrete and also hexagonal in shape to match the steel ribs. Anchor bars were provided inside the arch to maintain clean lines externally. The twelve $75 \mathrm{~mm}$ diameter bars were prestressed at this connection to prevent decompression of the concrete springings. Fabrication of the complex springing benefited from threedimensional (3D) modelling of the reinforcement layout (Figure 2(a)). The springing prestressing bars, ducts and bursting steel all had to be taken through the intersection with the main base reinforcement mat at a fine angle to the horizontal plane and tilted to the vertical plane. A temporary steel frame was required to support and maintain accuracy of the anchorage during concreting (Figure 2(b)). In the initial design, the two arches were braced together with four cross-girders. Two girders were located just below deck level and also supported 


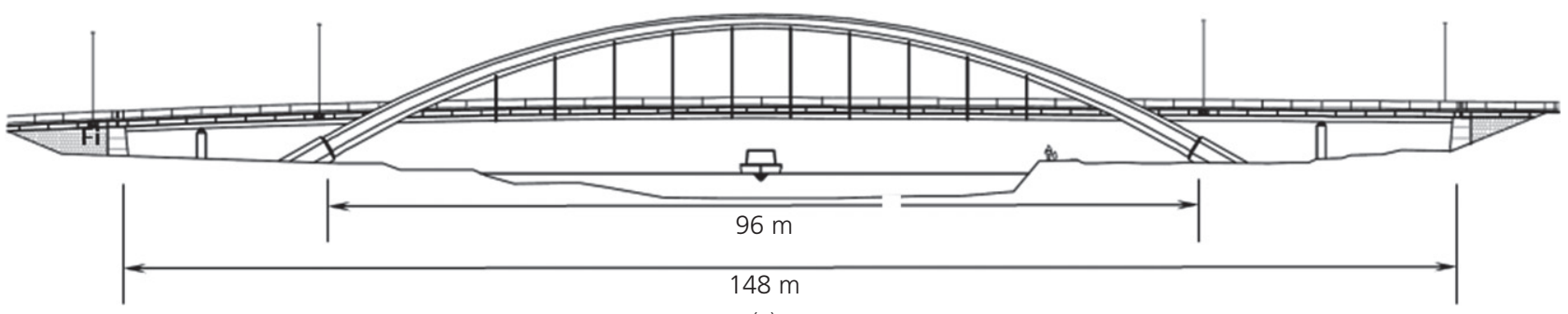

(a)

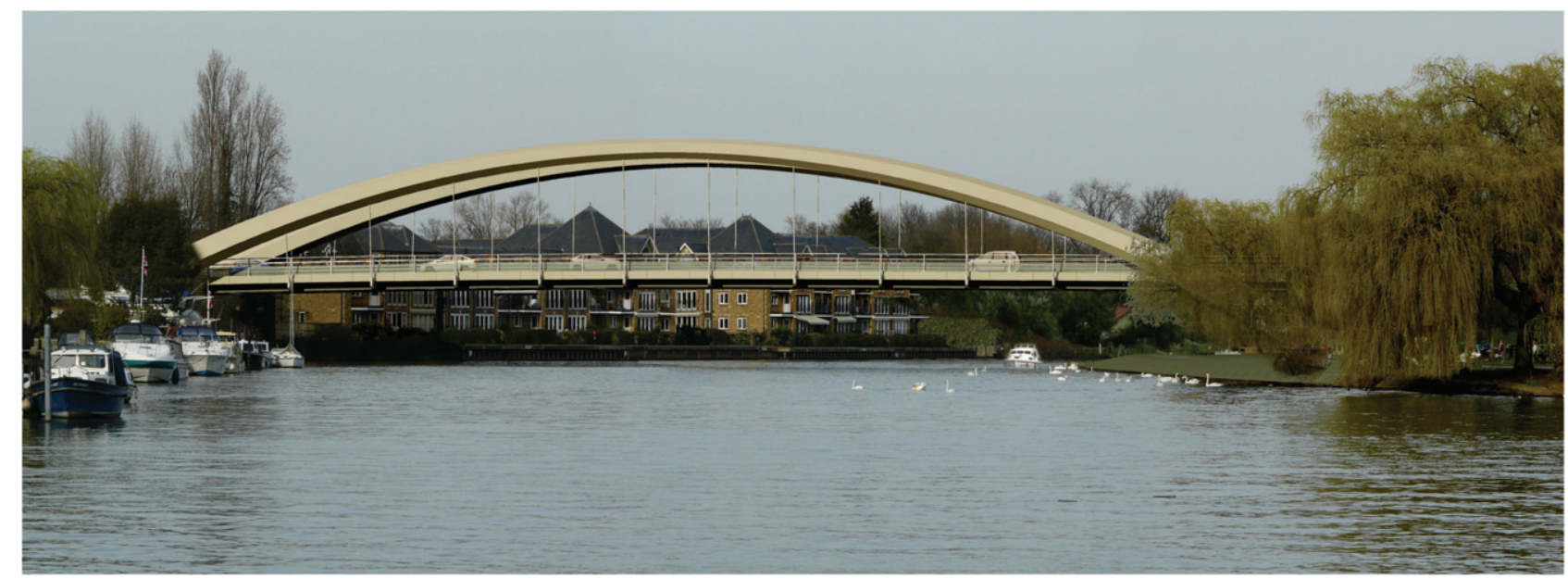

(b)

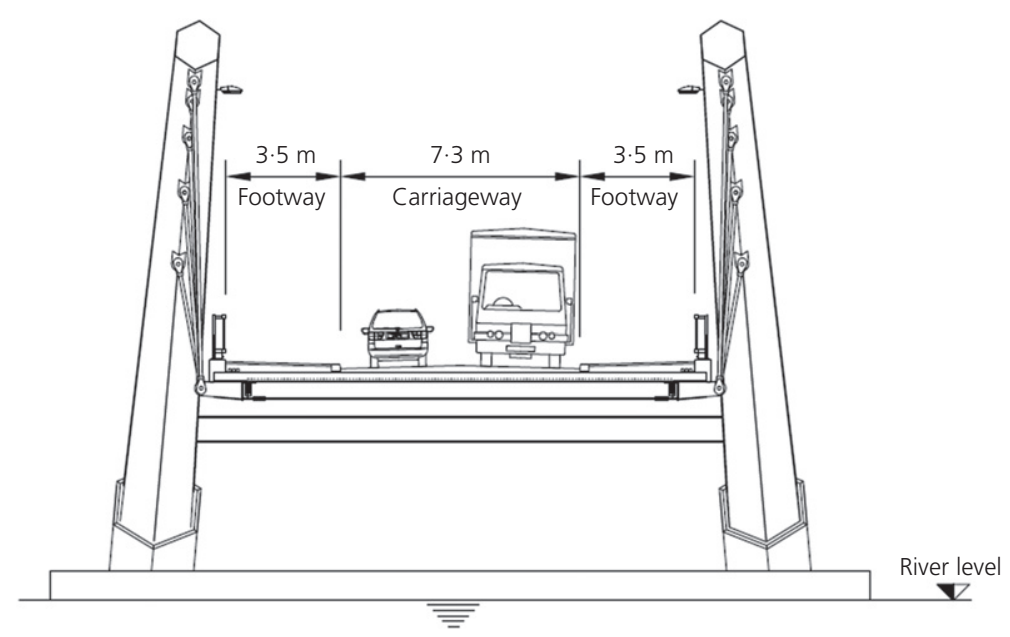

(c)

Figure 1. Walton Bridge: (a) General arrangement; (b) upstream photomontage; (c) Cross-section

the deck on pot bearings. Two others were provided at the crown. The main buckling modes of the arch were in the vertical plane, so the primary function of the crown cross-girders was to prop the lean of the arches. During design development, the decision was made to remove the top bracing to create a more open appearance, but this increased the out-of-plane moments in the arch.

The deck construction was kept as shallow as possible with $600 \mathrm{~mm}$ deep steel edge girders and a $250 \mathrm{~mm}$ thick 
Walton Bridge - a new arch bridge over

the River Thames, UK

Hendy, Smith and Chiarello

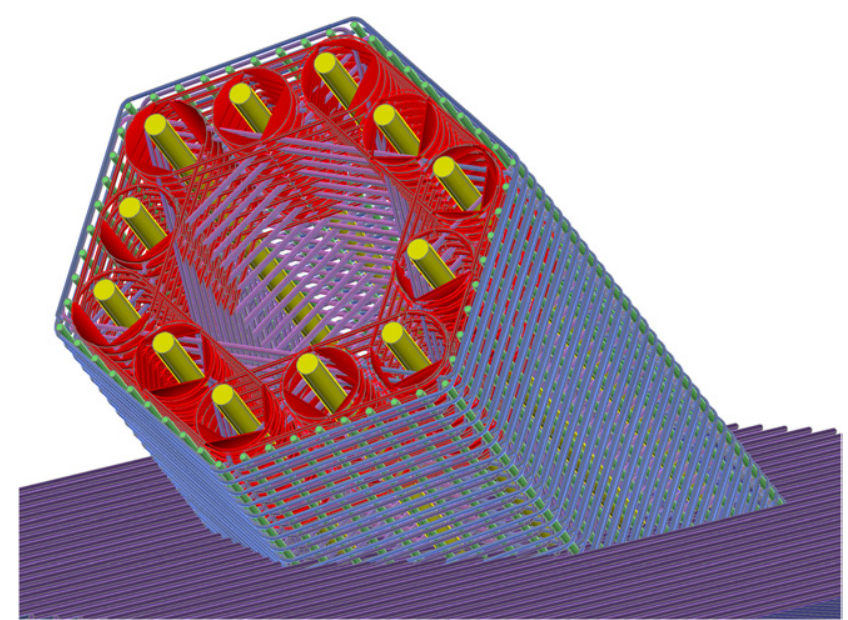

(a)

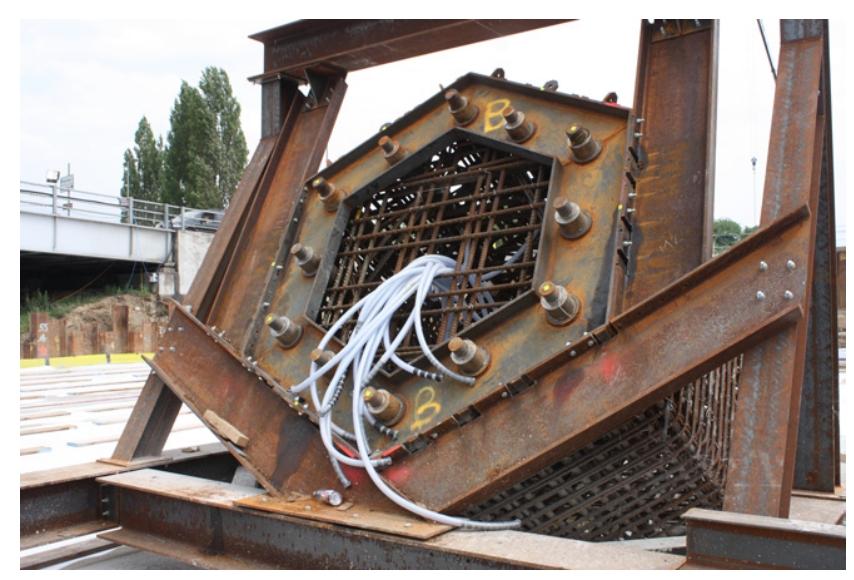

(b)

Figure 2. (a) 3D model of arch springing. (b) Springing fabrication and support frame

concrete slab in a ladder deck configuration. The original reference design featured box girders for all of the deck members, but the longitudinal edge beams were simplified to J-shaped girders, with no bottom flange outstand on the outside face, to keep the clean edge appearance but reduce fabrication cost. Further details on the design of $\mathbf{J}$ girders in general are given by Smith (2005). Deck details were kept simple with a $1.4 \mathrm{~m}$ vertical rail parapet (N1/W1 in accordance with TD 19/06 (HA, 2006)), incorporation of $800 \mathrm{~mm}$ tall solid Perspex noise barriers and LED highway lighting mounted on the arch. External feature lighting was not incorporated into the bridge design to mitigate light pollution. SCC's objective was to maintain the Cowey Sale public open space with a low level of district brightness, commensurate with a rural or relatively dark urban location (ILE, 2005).

\section{Global analysis}

\subsection{Bridge idealisation}

Global analysis of the superstructure was conducted using a 3D space frame model (Figure 3). The construction sequence was taken into account by considering appropriate transient design situations. The deck was modelled using a standard grillage arrangement and the arch box sections modelled as spine members along their centreline. Hangers were pinconnected to the arch ribs and deck.

All members were modelled using beam elements of varying cross-section. Analyses carried out on this global model included first-order static analysis, elastic critical buckling analysis and frequency analysis. The use of beam elements was advantageous at this stage to eliminate the generation of numerous local buckling modes associated with shell elements (as discussed by Hendy and Jones (2009)). More detailed shell analysis of the arch was undertaken later to introduce the effects of local bending and buckling in the curved arch plates as discussed in Section 4.

Foundation flexibility was incorporated into the models to ensure soil-structure interaction was accounted for. The bridge deck was fixed longitudinally at the lower cross-girder on the Shepperton side and guided longitudinally at the upstream side of the Walton side lower cross-girder. Other bearings were free sliding. The susceptibility of the structure to aerodynamic excitation was determined in accordance with the criteria given in BS EN 1991-1-4 (BSI, 2005b) and PD 6688-1-4 (BSI, 2009). Frequencies of the structure were generated using natural frequency analysis. Additional localised finite-element models were developed to determine the effects of vehicle impact actions on the steel arch ribs and for diaphragm design.

\subsection{Static analysis (persistent situation, hanger removal and accidental impact)}

The bridge design was carried out for the persistent situation and for the removal of a single hanger according to clause 2.3.6 of BS EN 1993-1-11 (BSI, 2006b). The hanger removal considerations comprised two different loading cases: deliberate, controlled hanger replacement (treated as a transient design situation) and accidental removal (treated as an accidental design situation). It was specified in the project brief that hangers should be replaceable under controlled conditions with reduced traffic load (i.e. one lane closure with half the bridge width loaded with group grla only and no load model 3 according to Table 4.4a of BS EN 1991-2 (BSI, 2003)). This was treated as a transient design situation, but with the same partial factors as for the persistent design situation. 


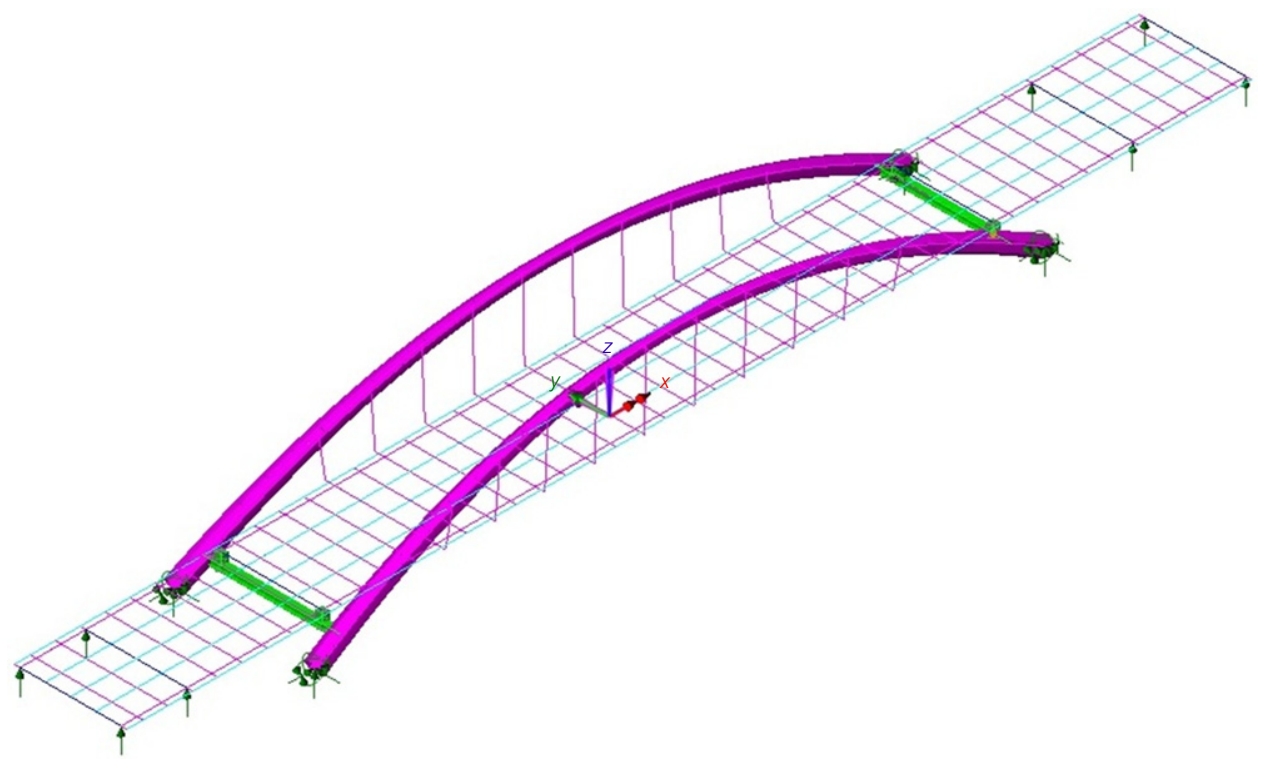

Figure 3. Global model idealisation

Accidental removal was treated as an accidental design situation considering two different scenarios

(a) instantaneous accidental removal of the hanger with the dynamic effect of hanger removal considered in accordance with Equation 2.4 of BS EN 1993-1-11 (BSI, 2006b)

(b) survival of the structure after the accidental removal of the hanger with the deck still open to traffic awaiting intervention.

Only one hanger was considered to be accidentally removed at any one time, making it essential that the hangers had adequate toughness to avoid a brittle failure under the shock loading. This is discussed further in Section 5. Of the two cases, the hanger replacement case was the most onerous; plastic resistance of the edge beam being used to increase the capacity for the accidental case.

\subsection{Analysis for the temporary condition during construction}

The construction sequence of the arch was agreed at an early design stage by the project team, which included the steelwork fabricator. Erecting the arch in one piece was initially discussed but dismissed as being too expensive. At about $280 \mathrm{t}$ in weight, each arch would have required specialised craneage to reach to the middle of the river. This would have had adverse cost and programme implications and would still have required temporary stabilisation.

The key questions for construction were how many temporary supports to provide in the river and the order of erection between arch and deck steelwork. Options of one, two or three temporary trestles per arch rib were evaluated. The most economical option was considered to be the use of a single central trestle tower to support a midspan welded splice (see Figure 4). The arch ribs were transported to site in sections and fabricated into two halves and then lifted onto temporary cradles at the springing and crown points. Having the cradles at the connecting positions gave the fabricator maximum fine control of the fit-up of the steelwork having de-rigged the crane. It also allowed torsional, lateral and vertical restraint to be provided for the temporarily simply supported sections of arch. Having only one tower minimised the temporary works

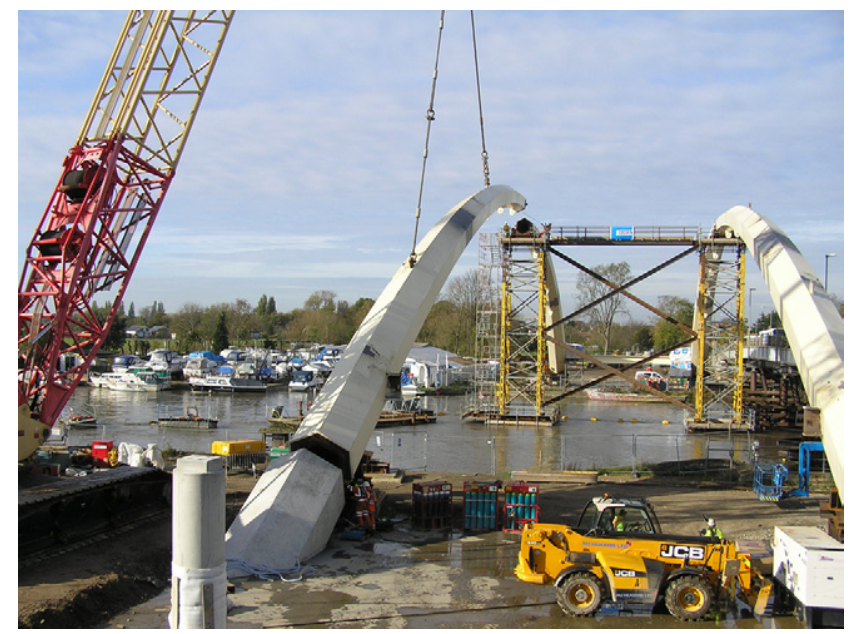

Figure 4. Bridge during erection 
within the river and the associated risks. The removal of the crown bracing also enabled the deck erection to proceed after the arch construction. The deck panels were designed so that a pair of cross-girders, $13.1 \mathrm{~m}$ long, could be lowered between the arch ribs and turned $90^{\circ}$ into their final position where the hangers could be attached.

The erection sequence was idealised in the following six stages for the design model.

- Half arches on trestles - the base and crown were not fixed so each half arch was simply supported.

- Cross-girders in place - the cross-girder was installed before the base was fixed, so the arch remained simply supported.

- Arch welded at the top and prestressed down onto the base, developing full continuity at midspan and full restraint at the base.

- Central trestle removed.

- Deck steelwork installed.

- Deck slab concreted in two stages from each abutment to meet at midspan.

Each of the construction stages was modelled in order to obtain the appropriate stress build up, primarily to predict the required precamber for the arch.

\subsection{Frequency analysis and aerodynamic check}

Figure 5 shows the fundamental bending and twisting modes and the frequencies at which they occur. These frequencies were subsequently used for aerodynamic checks.

Aerodynamic checks were carried out in accordance with BS EN 1991-1-4 (BSI, 2005b) and PD 6688-1-4 (BSI, 2009), despite them not directly covering arch bridges, implying that a wind tunnel test should be performed to assess the susceptibility of the structure to aerodynamic excitation. Clause NA.2.49.3 of the UK National Annex to BS EN 1991-1-4 (BSI, 2005b) further clarifies that '...cable supported bridges [...] should be considered as category (c)', which also then necessitates wind tunnel testing. In addition, the bridge does not comply with the codified geometric requirements, mainly because of the solid Perspex noise barrier. However, carrying out checks in accordance with BS EN 1991-1-4 and PD 6688$1-4$, it was clear that

- the aerodynamic susceptibility parameter $P_{\mathrm{b}}$ was very low $\left(P_{\mathrm{b}}=0 \cdot 041\right.$, just within the range $0 \cdot 04 \leq P_{\mathrm{b}} \leq 1$ where a check is required)

- the bridge was stable with respect to galloping and flutter because of the large deck width, so there was no risk of divergent amplitude vibrations leading to major structural damage
- the vortex shedding check did not produce accelerations that threatened ultimate limit state, serviceability limit state or fatigue performance

- existing bridges with similar geometry show no wind-induced vibration problems.

As a result, it was decided not to invest in wind tunnel testing and to monitor the bridge's performance once constructed as the risk of vibration problems was considered low. A similar decision was made with respect to possible vibration of the arch hangers where Stockbridge dampers could be installed retrospectively on the bars if excessive vibration was observed.

\section{Arch rib design}

\subsection{Section classification (based on non-linear finite-element analysis of a curved plate)}

The section classification of the arch cross-section required some consideration. Each plate making up the cross-section was assumed to be supported against out-of-plane buckling by adjacent plates; previous experience had shown that the internal angle between plates was sufficient to justify this. Hence, each component plate of width $c$ (Figure 6(a)) could be checked for compactness using Table 5.2 of BS EN 1993-1-1 (BSI, 2005c). As such, the cross-section of the arch was class 2 at springing points and class 1 at the crown. However, it was noted that for a many-sided figure this angular change could become too small for each plate to be considered individually and the section could become more akin to a tube of diameter $d$ (Figure 6(b)).

It is important to note, however, that the codified section classification limits apply to nominally flat plates whereas, for Walton Bridge, the plates forming the arch are curved in elevation. The design geometric imperfection for a nominally flat plate from Table C.2 of BS EN 1993-1-5 (BSI, 2006a) is $c / 200$ (i.e. $1250 / 200=6.25 \mathrm{~mm}$ (maximum) for Walton Bridge); however, at the base of the arch, the bow associated with the arch curvature is around $18 \mathrm{~mm}$ - almost three times this value. So, while a flat plate of these proportions would be class 2, the additional curvature for the Walton Bridge arch could affect strength and ductility and hence the section classification.

Three approaches were therefore taken to investigate the strength and ductility (compactness) of the component plates.

(a) The transverse bending stresses associated with the vertical arch curvature were calculated using PD 6695-2 (BSI, 2008) and combined with direct stresses from axial load using the von Mises equivalent stress criteria. This allowed derivation of a reduced design axial stress needed to cause yield, which could be used as a substitute for 


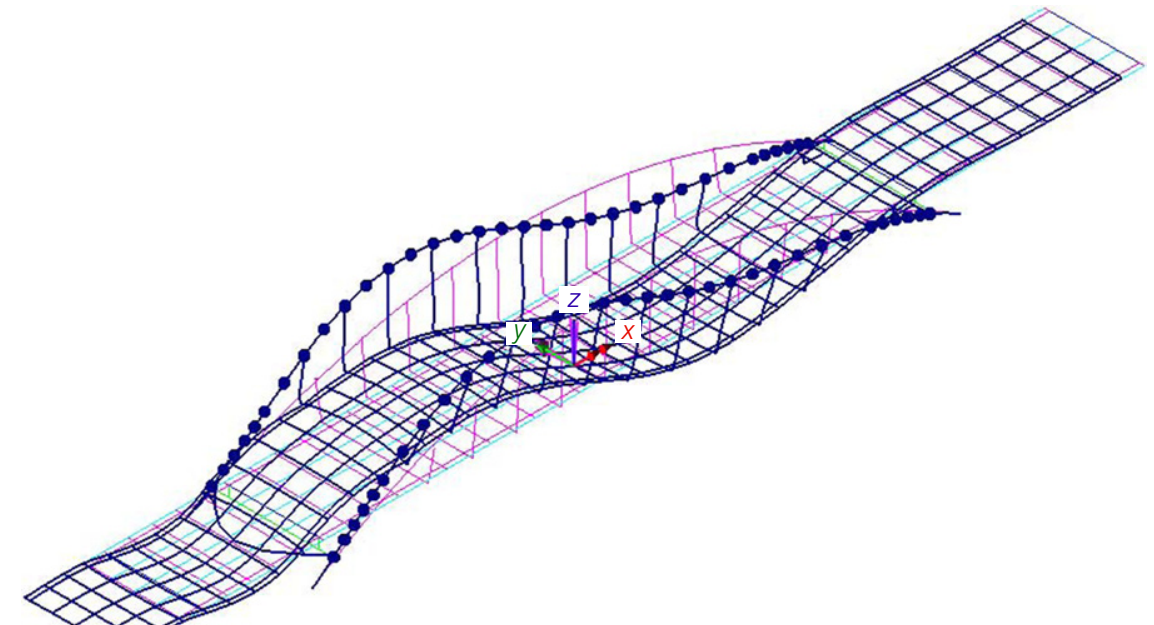

(a)

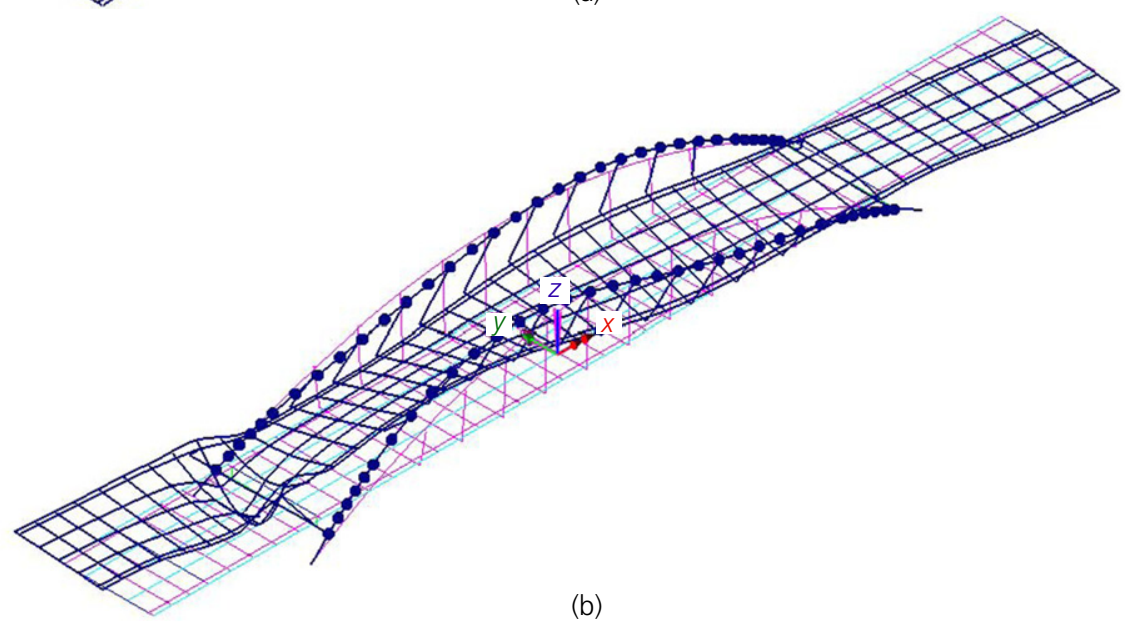

Figure 5. Bridge natural frequencies: (a) deck bending,

$f_{\mathrm{B}}=1.373 \mathrm{~Hz}$; (b) deck twisting, $f_{\mathrm{T}}=1.905 \mathrm{~Hz}$

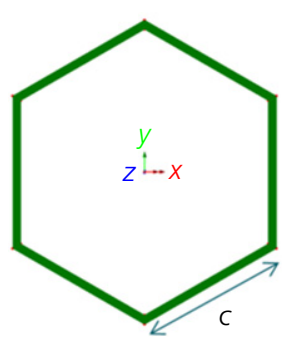

(a)

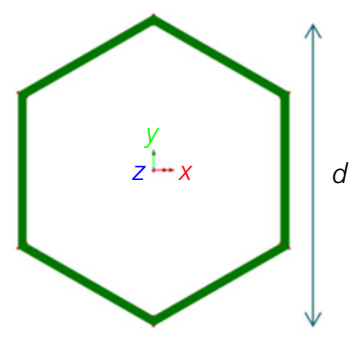

(b)
Figure 6. Section classification: (a) hexagonal section with each plate simply supported; (b) hexagonal section equivalent to a tubular section the yield stress to be used in subsequent calculations. This reduced the allowable axial stress by $3 \%$, to $0.97 f_{\mathrm{y}}$. Whilst this reduction in strength was small, suggesting class 2 behaviour might still be appropriate, the method made no prediction about ductility to justify class 2 behaviour.

(b) Figure T.3A of BD 56/10 (HA, 2010) was used to determine the plate axial resistance with an additional imperfection of three times the maximum allowed tolerance (as noted earlier). This method also made no prediction about ductility or the appropriateness of class 2 behaviour. It resulted in a reduction of allowable axial stress of $3 \%$ (i.e. $0 \cdot 97 f_{\mathrm{y}}$ ), similar to the first approach.

(c) Full non-linear modelling of the curved panel was carried out and compared with similar modelling of a nominally flat panel, as now discussed. 
For the non-linear analysis, the widest plate panel at the springing point section was modelled separately using thick shell elements. The panel shape was trapezoidal (due to the taper) but, for simplicity, it was modelled as rectangular based on the greatest width. Two models were created - one with the actual plate vertical curvature and another flat. The geometry was as follows
panel width $b=1250 \mathrm{~mm}$
- panel length $a=4250 \mathrm{~mm}$
- plate thickness $t=45 \mathrm{~mm}$
n plate radius $r=125000 \mathrm{~mm}$ (curved plate only)

The panels were modelled in isolation as simply supported plates. The loaded ends were subjected to axial stress using deflection control so that the maximum load would be recorded along with the stress-strain behaviour after the peak load was achieved. The following two generic analysis types were conducted.

(a) Eigenvalue analysis to determine elastic buckling modes. The lowest modes for the flat plate and the curved plate are shown in Figures 7 and 8 respectively. It can be seen that the curvature has minimal effect on these modes.

(b) A non-linear (material and geometric) analysis with material properties obtained from BS EN 1993-1-5 (BSI, 2006a) annex $C$ (incorporating the simple bi-linear stress-strain idealisation of strain hardening post-yield) and initial imperfections determined by eigenvalue analysis (for shape) and magnitude in accordance with BS

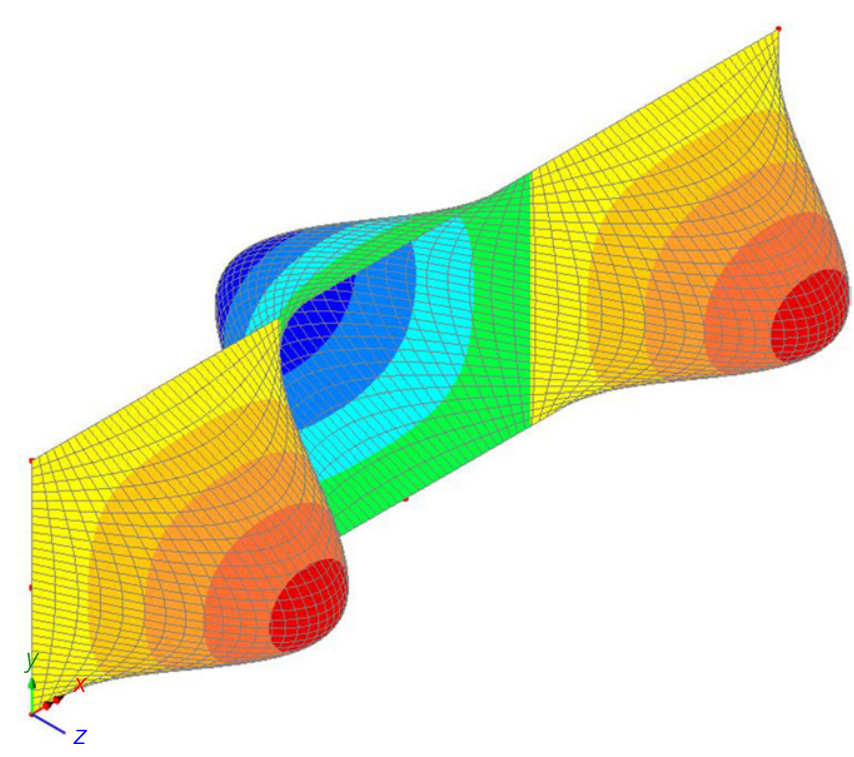

Figure 7. Lowest elastic buckling mode - flat plate (eigenvalue $=2 \cdot 916$ )

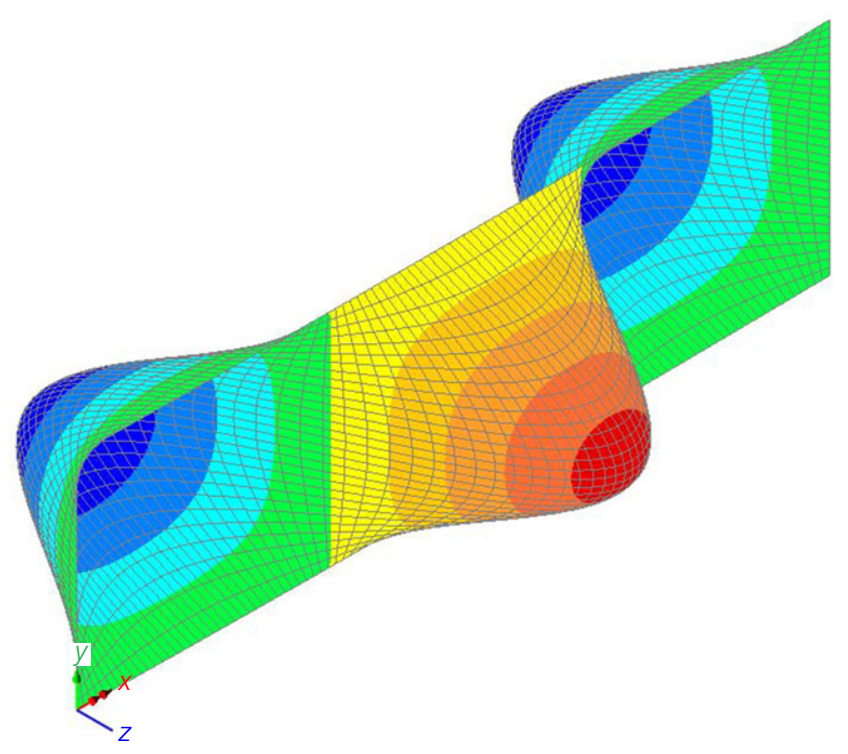

Figure 8. Lowest elastic buckling mode - curved plate (eigenvalue $=2 \cdot 634$ )

EN 1993-1-5 (BSI, 2006a) annex C. Several different mode shapes were tried in this analysis to minimise the ultimate load factor. Load-deflection curves are shown for the flat and curved plates in Figure 9. The load is based on fraction of yield force for the entire panel.

The non-linear analysis showed that the peak load for the curved plate was approximately $2 \%$ less than that for the flat plate (i.e. $0 \cdot 965 f_{\mathrm{y}}$ compared with $0 \cdot 982 f_{\mathrm{y}}$ ). This agrees well with the value of $0.97 f_{\mathrm{y}}$ obtained from the two simple approaches listed earlier. The flat plate did not quite reach the full yield force (contrary to expectations for a class 2 section) because the codified imperfections to be used are very conservative. The design code formulae for plate buckling resistance have a slenderness-dependent imperfection that reduces at low slenderness so that yield is achieved in line with physical testing results. To achieve the same result in non-linear analysis with the full imperfections would have required a more detailed modelling of the true stress-strain behaviour post-yield.

The ductility for the curved plate was significantly reduced from the flat plate value. Again, this was a function of the conservative imperfection used and the lack of detailed consideration of strain-hardening in the stress-strain curve. The top curve in Figure 9, with a long yield plateau, shows how much ductility is achieved with no initial imperfection. As a result, it was concluded that the plate had adequate ductility to still permit class 2 behaviour, but a conservative value of equivalent yield stress was derived for use in section design. This was taken as $0.95 f_{\mathrm{y}}$, based on the value of stress in the curved plate 


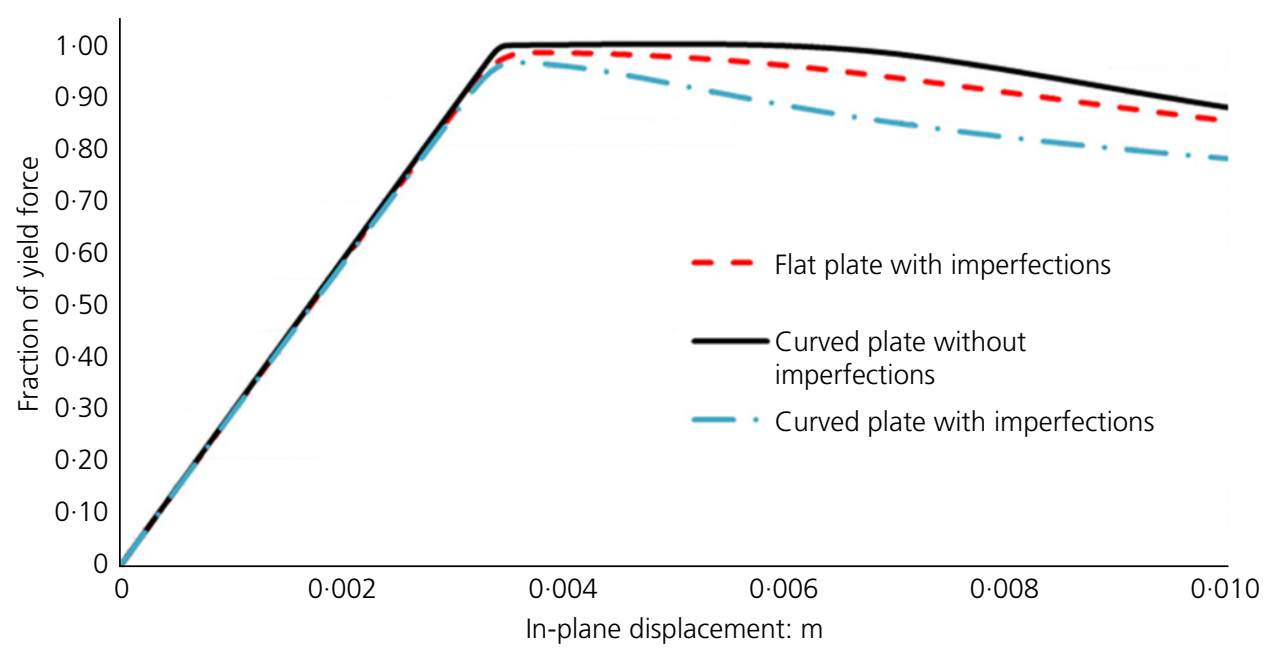

Figure 9. Load-deflection behaviour for flat and curved panels

at the same strain at which the flat plate started to lose load. It was considered that the true behaviour would be nearer to that obtained with zero additional imperfection but to prove this would have necessitated a considerably longer study.

\subsection{Buckling analysis for arch girder design}

The slenderness for arch buckling was determined from Equation 5.11 of BS EN 1993-1-1 (BSI, 2005c) according to

$$
\bar{\lambda}=\sqrt{\frac{\alpha_{\mathrm{ult}, \mathrm{k}}}{\alpha_{\mathrm{cr}}}}
$$

in which $\alpha_{\mathrm{ult}, \mathrm{k}}=N_{\mathrm{Ed}} / N_{\mathrm{Rk}}\left(N_{\mathrm{Ed}}\right.$ is the arch axial force at the section considered and $N_{\mathrm{Rk}}$ is the arch characteristic crosssectional resistance at the same section) and $\alpha_{\mathrm{cr}}$ is the minimum load factor against elastic critical buckling of the arch as a whole.

The elastic critical buckling factor $\alpha_{\mathrm{cr}}$ was determined as the lowest of the buckling factors for in-plane and out-of-plane buckling ( $\alpha_{\mathrm{cr}, i p}$ and $\alpha_{\mathrm{cr}, \mathrm{op}}$ respectively) obtained from an eigenvalue analysis of the completed bridge. Figures 10(a) and 10 (b) show the modes producing the lowest load factors for outof-plane buckling and in-plane buckling respectively.

As a check, the critical arch buckling axial forces from the elastic critical buckling analysis, obtained as $\alpha_{\mathrm{cr}} N_{\mathrm{Ed}}$ with $N_{\mathrm{Ed}}$ taken at the arch springing points, were compared with the buckling loads calculated from three simpler approaches.

- Case A: a separate model of a single arch rib in isolation with variable section properties modelled and hanger forces applied as loads.
Case B: a separate model of a single arch rib in isolation with constant section properties (taken as the average of the middle third values) and hanger forces applied as loads.

- Case C: using annex D.3 of BS EN 1993-2 (BSI, 2006c), which gives critical buckling loads for in-plane and out-of-plane buckling for an arch of constant section.

Table 1 summarises the results obtained from these three different approaches and the elastic critical buckling analysis of the full model. This shows the benefit of modelling the arch cross-section variation accurately (which significantly affects the in-plane buckling load) and the significant benefit of modelling lateral restraints to the arch from both the hangers (via their connection to the deck) and the lower cross-girders. Case A illustrates that the lateral restraints have little impact on the in-plane buckling load $\left(N_{\text {cr,ip }}\right)$, but more than double the out-of-plane buckling load $\left(N_{\mathrm{cr}, \mathrm{op}}\right)$.

Once the slenderness was determined, the strength reduction factor $(\chi)$ for compression resistance was obtained from clause 6.3.1.2 of BS EN 1993-1-1 (BSI, 2005c). In addition to axial force, the arch is subjected to first-order in-plane bending moments $\left(M_{y, \mathrm{Ed}}\right)$ and out-of-plane bending moments $\left(M_{z, \mathrm{Ed}}\right)$. The arch compression magnifies these first-order bending moments and the following conservative interaction was adopted to consider the combined effect of the axial force and bending moments

$$
\frac{N_{\mathrm{Ed}}}{\chi N_{\mathrm{pl}, \mathrm{Rd}}}+\frac{1}{1-\left(1 / \alpha_{\mathrm{cr}, \mathrm{ip}}\right)} \frac{M_{y, \mathrm{Ed}}}{M_{y, \mathrm{Rd}}}+\frac{1}{1-\left(1 / \alpha_{\mathrm{cr}, \mathrm{op}}\right)} \frac{M_{z, \mathrm{Ed}}}{M_{z, \mathrm{Rd}}} \leq 1 \cdot 0
$$




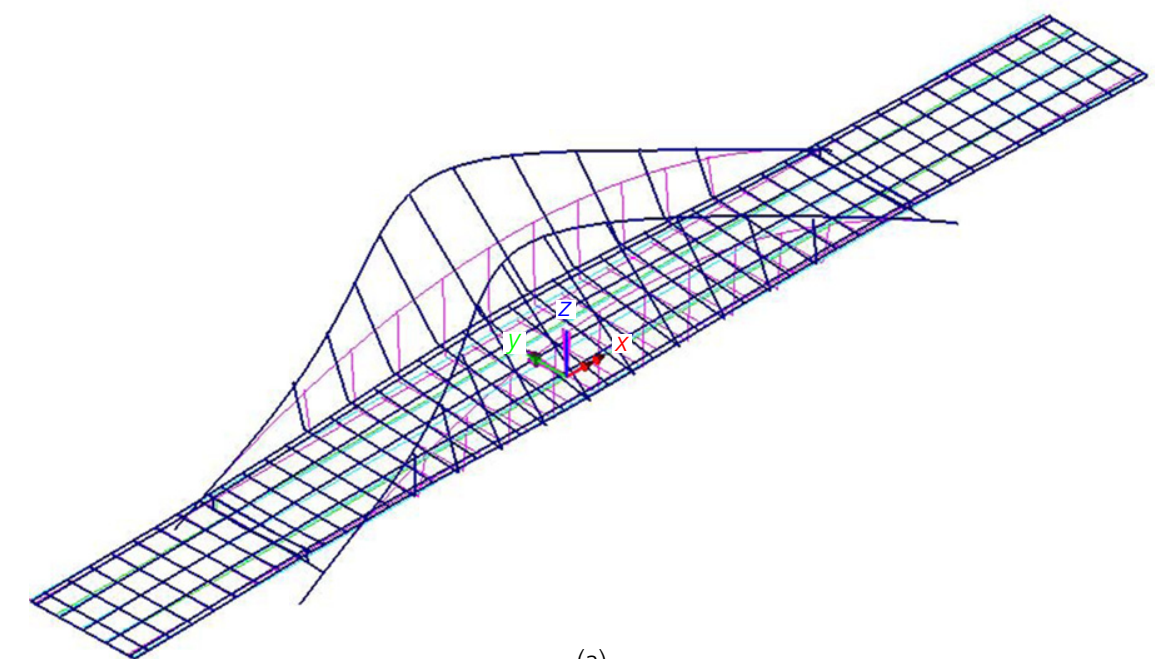

(a)

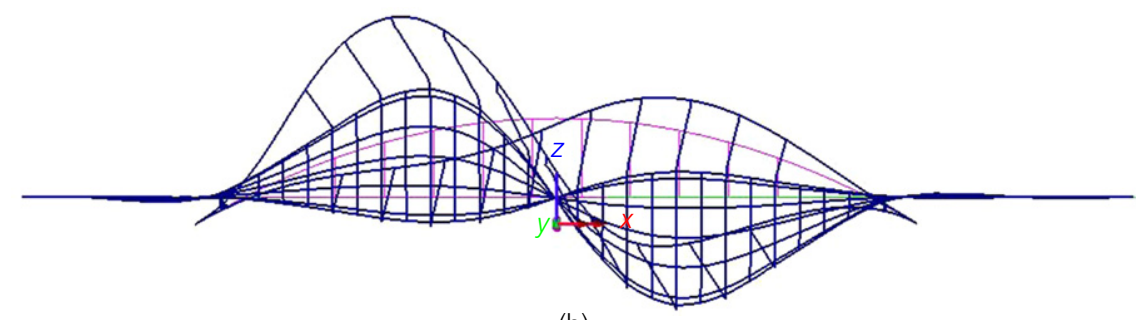

(b)

Figure 10. Load factors produced with elastic critical buckling

analysis: (a) load factor for out-of-plane buckling mode,

$\alpha_{c r, o p}=8 \cdot 77$; (b) load factor for in-plane buckling mode,

$\alpha_{\mathrm{cr}, \mathrm{ip}}=9 \cdot 81$

\section{Critical buckling load: MN}

Table 1. Elastic critical buckling calculation comparisons

$M_{y, \mathrm{Rd}}$ and $M_{z, \mathrm{Rd}}$ are the plastic bending resistances calculated using the reduced value of equivalent yield stress for a curved plate discussed in Section 4.1. In most load cases, $M_{y, \mathrm{Ed}}$ and $M_{z \text {,Ed }}$ were not distributed in similar form to the additional moments arising from the buckled shape and therefore amplifying $M_{y, \mathrm{Ed}}$ and $M_{z, \mathrm{Ed}}$ by the above factors was conservative.
However, since the buckling factors were relatively high, the magnification factors were relatively small and the conservatism could be tolerated. The first term above is also conservative in the interaction since the maximum fibre stress produced under axial force does not increase linearly with the axial force because of the non-linear magnification of the moments from 
imperfections. This issue of interaction between axial force and bending moments in steel arches is discussed in greater detail by Baird et al. (2011).

For the design of the arch connection to the concrete plinth, the twisting moment at the arch springing point was also amplified by the factor $1 /\left[1-\left(1 / \alpha_{\mathrm{cr}, \mathrm{op}}\right)\right]$ since the out-of-plane buckling mode increases the torque developed.

\section{Hanger design, test and specification}

The hangers comprised steel bars with fork end connections. The optimal hanger fork orientation depends mainly on the plane where the greatest rotation is expected from bridge articulation and deflections. For Walton Bridge, hangers were detailed to be free to rotate transversely, top and bottom. It was then checked that thermal movement plus construction tolerances did not produce excessive angular deviation and stress in the end connections. The hanger manufacturer specified a maximum angle of approximately $0.5^{\circ}$, which corresponded to the allowable angular change before the gap inside the fork closed and the fork and gusset would lock, creating significant additional bending stress in the connection and bar. The design angular deviation was kept below this value, the hanger installation angles were preset to allow for temperature at the time of construction, and fatigue testing of the bars and end connections was carried out incorporating this maximum design deviation angle.

If the rotation had exceeded the permissible limit, a system incorporating spherical bearings could have been considered, but preliminary investigations suggested that the bearing frictional torque (based on the upper bound friction value) could still produce significant bending stresses.

Hangers were connected to the cross-girders by gusset plates at deck level and directly to the vertical diaphragm at the arch ribs. The option of connecting the gusset plate to the arch box section walls was considered but then dismissed due to the risk of laminar tearing at the connection. The agreed connection detail involved passing the vertical diaphragm plate, incorporating the gusset plate, through a slotted hole in the arch bottom flange (Figure 11).

The design value of the tension resistance of the entire hanger system is the minimum value of the design tension resistance of the rod, turnbuckle and design bearing resistance of the gusset plate. The design axial resistance at serviceability and ultimate limit states is well described by BS EN 1993-1-11 (BSI, 2006b). Manufacturers of bars have readily available information for static strength.

What became apparent in the design of the hangers was that bar manufacturers currently do not have data available for fatigue performance of their systems, nor could they advise on requirements for toughness. As such, the specification for Walton Bridge had to set out performance requirements for these and required testing to demonstrate compliance.

Fatigue testing requirements for bars are also covered by BS EN 1993-1-11 (BSI, 2006b). The Walton Bridge specification required testing of the bars, incorporating connection details and the angular misalignment, for two million cycles at a stress range equal to $1 \cdot 25$ times the damage equivalent stress range calculated by applying fatigue load model 3 of BS EN 1991-2 (BSI, 2003). The test stress range was applied such that the maximum stress in a cycle was $0 \cdot 45 \sigma_{\mathrm{uk}}$. This corresponds to the serviceability limit state limiting stress of $0.45 \sigma_{\mathrm{uk}}$ in Table 7.2 of BS EN 1993-1-11 (BSI, 2006b), which is intended to help reduce the likelihood of fatigue but is not itself a check of fatigue. These fatigue tests were successfully carried out and demonstrated that the bar system complied with the requirements for Walton Bridge.

Brittle fracture requirements for bars were found to be less readily determined from codes than for plates. Table 2.1 of BS EN 1993-1-10 (BSI, 2005d), with the UK National Annex, was used to determine Charpy requirements for the bars, but this standard only really applies to plates and application is

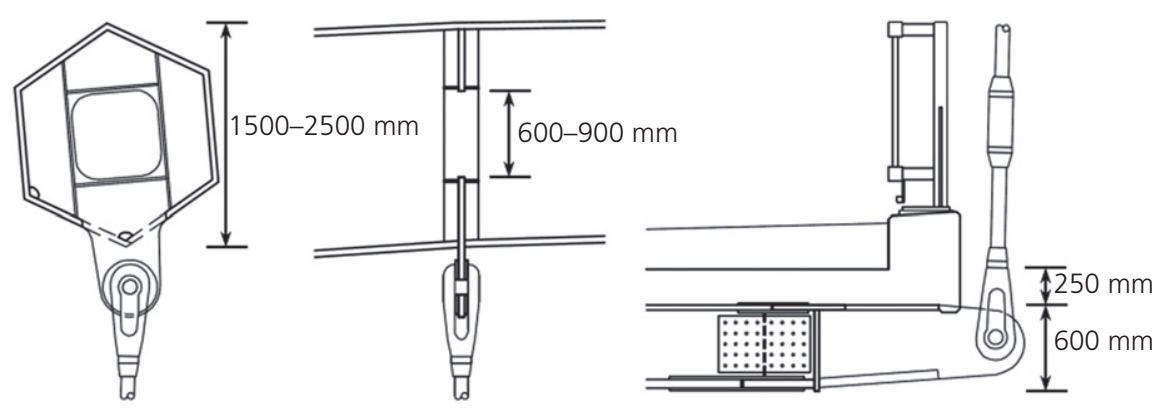

Figure 11. Hanger connection details 
limited to steel grades of $700 \mathrm{MPa}$ yield strength and below. The hangers on Walton Bridge were $100 \mathrm{~mm}$ diameter and had a yield strength of $690 \mathrm{MPa}$. A high Charpy requirement resulted, corresponding to steel sub-grade QL1 to BS EN 1993-1-10 (BSI, 2005d). It is considered that applying the rules for plates to bars is conservative (because, for example, Table 8 in BS EN 10083-3 (BSI, 2006d) has different requirements for bars and plates, where limiting dimensions for bars are roughly double those for equivalent plates) but this could not be confirmed within the project. For Walton Bridge, the Charpy values obtained from the tests on the actual bars supplied were high enough to comply with this requirement. However, it would generally be advisable to consider use of a lower steel strength grade for hangers to avoid such a high toughness requirement that may be impossible to procure.

A fracture mechanics approach could also have been adopted, as suggested in clause 2.4 of BS EN 1993-1-10 (BSI, 2005d). This was carried out as a check on the specified hangers with their specified toughness requirements and a critical flaw size for fracture was determined. The fracture toughness $\left(K_{1 \mathrm{c}}\right)$ was obtained from a correlation with the Charpy value $\left(C_{\mathrm{v}}\right)$ using BS 7910 (BSI, 2005a) annex J, which gives the following relationship for lower shelf behaviour, which is appropriate for use at the minimum design service temperature

$$
K_{1 \mathrm{c}}=\left[\left(12 \sqrt{C_{\mathrm{v}}}-20\right)\left(\frac{25}{B}\right)^{0.25}\right]+20
$$

in which $B$ is the bar diameter.

The modest size of the flaw derived for this fracture toughness further suggested that higher strength bars should generally not be used for bridge hangers because critical cracks leading to fracture may be undetectable.

The bridge was designed to stand up in the event of sudden failure of one hanger to mitigate the risk of brittle fracture in addition to the requirement to mitigate the consequences of vandalism or vehicle impact. Discussions on the relative merits of different hanger systems (bars versus cables formed of multiple wires) is beyond the scope of this paper but the drivers for selecting bars on Walton Bridge were lower cost and better aesthetics. Cable systems would have provided greater fatigue and fracture resistance, together with more redundancy because failure of any one wire would not trigger failure of the cable.

Wind-induced vibration may also induce fatigue damage so it must be adequately investigated. BS EN 1993-1-11 (BSI, 2006b) requires consideration of wind-induced vibration during and after erection of cables. Wind-induced vibration presenting fatigue risk is usually caused by vortex shedding because this phenomenon is usually associated with relatively low wind speeds and therefore could occur frequently. Clause 8.3(6) of BS EN 1993-1-11 (BSI, 2006b) imposes a limit of $L / 500$ (where $L$ is the length of the cable) on the amplitude of vibration with a moderate wind velocity of $15 \mathrm{~m} / \mathrm{s}$. The amplitude of wind-induced vibration can be estimated by hand calculation referring to annex E of BS EN 1991-1-4 (BSI, 2005b) or an alternative design code and by bespoke design software and specialist advice. However, only measurements on site will be conclusive. For this reason, it was recommended for Walton Bridge that wind-induced vibration was recorded on site once the bridge was constructed for the designer to make an assessment prior to demobilising the site.

Details of the Walton Bridge hanger specification were made available to the Steel Construction Institute with a view to producing an industry model specification.

\section{Finishes}

Surrey County Council had high expectations for the appearance of the bridge and was particular in specifying the finishes. In order to create an arch profile as close as possible to the parabolic curve, the arch side plates were cut using a series of $0.5 \mathrm{~m}$ and $1.0 \mathrm{~m}$ straight sections to follow the parabola. Top and bottom plates were not subdivided, but were pressed into position to suit the arch curvature. Concerns were also raised that welds would be visible and might also create distortion of the plates. Construction details were discussed extensively with the steel fabricator in order to limit problems associated with plate distortion. The relative thickness of the welded plates was taken into account and weld design was optimised to minimise costs, especially as there was no possibility of using automated welding processes for the arches. All the welds necessary to form the arch hexagonal section were made manually and then ground to meet the client's requirements. In general, the benefit of involving the fabricator at the early stages of design and detailing was highly evident through the relatively small number of changes made to detailing at fabrication stage. Figure 12 shows an arch girder during construction in the fabrication shop.

Three weld finishes were prepared in a trial mock-up by Mabey Bridge: fully ground weld ('soft disc'), partially ground weld ('hard disc') and 'as-welded'. All three types were then painted both gloss and semi-gloss for a comparison of paint finishes. The partially ground, gloss finish was finally selected for full fabrication. This also aligns with current Steel Construction Institute guidance that fully ground welded finishes are still visible after final painting. All of the steelwork was protected with a zinc-rich epoxy primer paint system known as the CTRL system. 

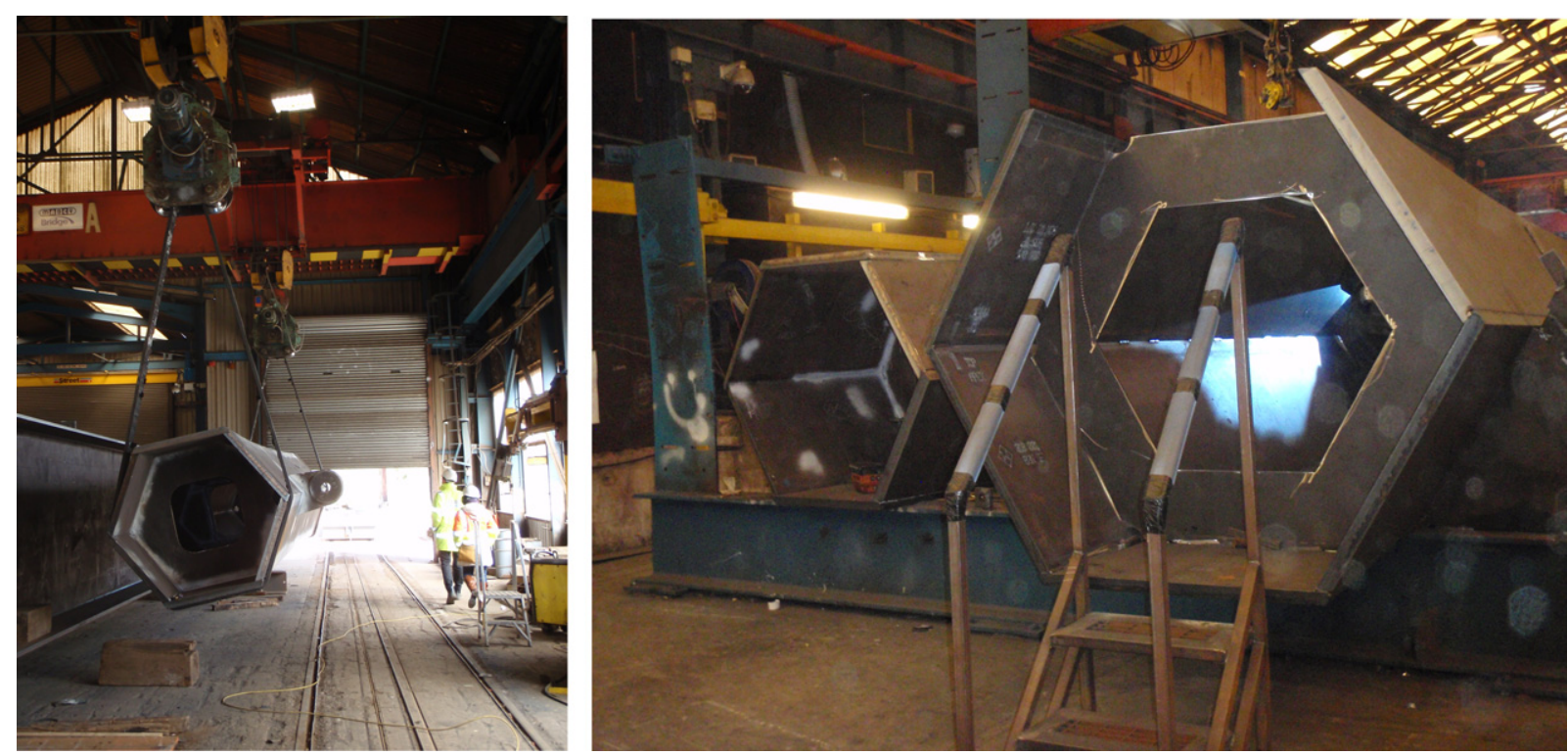

Figure 12. Arch girder fabrication in Mabey Bridge shop in Chepstow

A flush appearance was required for the access doors provided at the base of the two arch girders. A bespoke system of hinges, hidden from the view, was thus designed.

The project ecologist on the Walton Bridge scheme became concerned that local swans would be at risk of collision with the bridge hangers until they became used to the new obstacle. This led to the specification of 'flight diverters' (large discs) to be hung from the arch ribs during construction. The ecologist suggested that these would only be needed until permanent street lighting was in operation. These measures should be considered indicative of the need to consult an ecologist on issues specific to the site, rather than a universal requirement to protect swans.

\section{Conclusion}

This paper described the analysis and design of Walton Bridge generally and discussed how the need for aesthetics was balanced with efficient design both in terms of buildable details (through early discussions with the fabricator) and optimised material quantities (through appropriate structural analyses). In addition, solutions for dealing with a number of generic issues affecting steel arch design were developed and advanced. In particular, these included

- consideration of arch continuous vertical curvature and its effect on compactness and limiting stresses for the component plates
- design and specification of bar-type arch hangers for brittle fracture and fatigue to address a current shortfall in available industry standards and guidance on either subject.

The solutions presented in this paper should lead to both lighter arch construction through the selection of appropriate section classification for curved plates and safer specification of bar hangers.

The construction of Walton Bridge commenced on site in February 2011 and was opened to traffic in July 2013.

\section{Acknowledgement}

The authors would like to acknowledge Costain Limited and Surrey County Council for permission to publish this paper. Steelwork fabrication was undertaken by Mabey Bridge.

\section{REFERENCES}

Baird D, Hendy CR, Wong P et al. (2011) Design of the Olympic Park Bridges H01 and L01. Structural Engineering International 21(4): 8-15.

BSI (2003) BS EN 1991-2: Eurocode 1 - Actions on structures Part 2: Traffic loads on bridges. BSI, London, UK.

BSI (2005a) BS 7910: Guide to methods for assessing the acceptability of flaws in metallic structures. BSI, London, UK. 
BSI (2005b) BS EN 1991-1-4: Eurocode 1 - Actions on structures - Part 1-4: General actions - wind actions. BSI, London, UK.

BSI (2005c) BS EN 1993-1-1: Eurocode 3: Design of steel structures - Part 1-1: General rules and rules for buildings. BSI, London, UK.

BSI (2005d) BS EN 1993-1-10: Eurocode 3 - Design of steel structures - Part 1-10: Material toughness and through-thickness properties. BSI, London, UK.

BSI (2006a) BS EN 1993-1-5: Eurocode 3: Design of steel structures - Part 1-5: Plated structural elements. BSI, London, UK.

BSI (2006b) BS EN 1993-1-11: Eurocode 3 - Design of steel structures - Part 1-11: Design of structures with tension components. BSI, London, UK.

BSI (2006c) BS EN 1993-2: Eurocode 3: Design of steel structures - Part 2: Steel bridges. BSI, London, UK.

BSI (2006d) BS EN 10083-3: Steels for quenching and tempering - Part 3: Technical delivery conditions for alloy steels. BSI, London, UK.
BSI (2008) PD 6695-2: Recommendations for the design of bridges to BS EN 1993-2. BSI, London, UK.

BSI (2009) PD 6688-1-4: Background paper to the UK National Annex to BS EN 1991-1-4. BSI, London, UK. HA (Highways Agency) (2006) TD 19/06: Requirement for Road Restraint Systems. HA, London, UK.

HA (2010) BD 56/10: The Assessment of Steel Highway Bridges and Structures. HA, London, UK.

Hendy CR and Jones RP (2009) Lateral buckling of plate girders with flexible restraints. Proceedings of the Institution of Civil Engineers - Bridge Engineering 162(1): 25-33, http://dx.doi.org/10.1680/bren.2009. 162.1.25.

ILE (Institute of Lighting Engineers) (2005) Guidance Notes for the Reduction of Obtrusive Light. ILE, Rugby, UK.

Smith DA (2005) Refurbishment of the Old Medway Bridge, UK. Proceedings of the Institution of Civil Engineers Bridge Engineering 158(3): 129-139, http://dx.doi.org/ 10.1680/bren.2005.158.3.129.

\section{HOW CAN YOU CONTRIBUTE?}

To discuss this paper, please email up to 500 words to the editor at journals@ice.org.uk. Your contribution will be forwarded to the author(s) for a reply and, if considered appropriate by the editorial board, it will be published as discussion in a future issue of the journal.

Proceedings journals rely entirely on contributions from the civil engineering profession (and allied disciplines). Information about how to submit your paper online is available at www.icevirtuallibrary.com/page/authors, where you will also find detailed author guidelines. 